\title{
Transfer suppression of a hunger-motivated response as a function of the number of prior escape or avoidance trials
}

\author{
GERALD R. STOFFER \\ Pacific Lutheran University, Tacoma, Washington 98447 \\ and \\ HAROLD BABB
State University of New York at Binghamton, Binghamton, New York 19901
}

\begin{abstract}
Several prior studies have demonstrated suppression of an appetitively motivated response (relative to controls) acquired on the basis of prior aversive motivation. These studies used a small number of escape-acquisition trials prior to transferring a runway response across drive-reinforcement conditions. The present study was an attempt to determine if an avoidance procedure, as well as an escape procedure, in the aversive phase, would produce suppression in transferring to hunger-motivated responding. It also constituted an effort to determine the influence of extended aversive training on the degree of suppression. Four experimental groups of rats were used in a 2 by 2 factorial study (aversive condition: escape or avoidance by number of aversive trials: 15 or 45). Each group was subsequently food deprived and transferred to hunger-motivated responding in the same runway. The experimental groups started and ran at about the same suppressed speeds, relative to a hunger-motivated control group given no prior aversive training. These results replicate the basic suppression effect and extend it to animals given prolonged aversive training. Further, the effect is demonstrable with prior avoidance as well as with prior escape training. Possible explanations of suppression are presented.
\end{abstract}

Several studies have shown that, contrary to certain theoretical expectations (Hull, 1943), a specific response that has been appropriately reinforced under one drive condition does not profit from such experience when transferred to a second-drive reinforcement condition, albeit the same specific response is reinforced. In particular, animals transferred from shock-escape training to either hunger- or thirst-motivated training for the same runway response display suppressed speeds in the appetitive phase relative to control subjects which have had no prior escape training (Babb, 1963b; Babb, Bulgatz, \& Matthews, 1969; Babb \& Leask, 1969; Bulgatz, 1969).

The purpose of the present study was to provide further systematic replication of the basic suppression effect. Prior research by Babb and his associates had consistently used a small number (15) of escape-acquisition trials during the aversive phase. An attempt was made to extend suppression to animals given prior avoidance training and to assess the effects of an increased number of escape or avoidance acquisition trials on appetitive performance. Four groups of rats were first trained in a runway to avoid or escape electric shock. The subjects

This investigation was supported in part by Grant MH-11183 from the National Institute of Mental Health to H. Babb and by a National Defense Educational Act Fellowship to G. R. Stoffer. were then food deprived and retrained in the same situation to run for food reinforcement. Their performance was compared with that of a control group given no prior runway training.

\section{METHOD}

Subjects. The subjects were 45 naive male Long-Evans rats approximately 90-130 days of age on the 1st day of pretraining. There were nine animals (selected randomly) in each of the four experimental groups and in the control group.

\section{Apparatus}

A 4-ft runway with 1 - $\mathrm{ft}$ startbox and goalbox extensions, described more fully elsewhere (Babb et al., 1969), was used. Hunter infrared light relays, silent timers, an Applegate constant current shock generator, and a Davis shock scrambler were used to measure speed and to energize the startbox and runway grids. A Grason-Stadler $455 \mathrm{c}$ white noise generator was used to produce a $68-\mathrm{dB}$ sound stimulus (peak ambient noise level was $60 \mathrm{~dB}$ ).

\section{Procedure}

Pretraining. Each subject was given $3 \mathrm{~min}$ of handling each day for 5 days. Then for 7 days, subjects were placed on 22 -h food deprivation and individually given $3 \mathrm{~min}$ access each day to a tray of food on a metal table. The food tray was also used later in the goalbox. Pretraining was conducted in a room separate from that in which the experimental sessions were held.

Aversive motivation phase. Ad-lib feeding was initiated immediately following the last pretraining session. Experimental trials began the 2 nd day following pretraining. There were two shock-escape and two shock-avoidance groups, each of which were given five trials per day, totaling either 15 or 45 trials. The 
treatment groups (15 escape trials, 45 escape trials, 15 avoidance trials, and 45 avoidance trials) will be designated as E-15, E-45, A-15, and A-45, respectively. The 15-trial groups started training on the 7th day of the 45-trial groups' training.

For the shock-escape groups, a 1-mA shock was applied simultaneously with the opening of the startbox door and terminated as the subject entered the goalbox. For the shock-avoidance groups, the sound stimulus was presented simultaneously with the opening of the startbox door but preceded shock $(1 \mathrm{~mA})$ presentation by $3 \mathrm{sec}$. The sound stimulus (and shock for avoidance failures) terminated when the subject entered the goalbox.

The startbox door was opened at random intervals $(15,20,25$, or $30 \mathrm{sec}$ ) after the subject had been placed in the startbox. The times were the same for all subjects on any particular trial, however. At the end of each run, subjects were allowed to remain in the goalbox $30 \mathrm{sec}$ before being returned to individual retaining cages to await the next trial. The intertrial interval was approximately $8 \mathrm{~min}$.

Appetitive motivation phase. Following the aversive training phase, all subjects were placed on a 22 -h food deprivation schedule. The body weight of each subject was recorded prior to testing each day. Appetitive training began the 2 nd day after the conclusion of aversive training and continued for 65 trials at the rate of five trials per day. In addition, a 22-h hunger-motivated control group of rats (hereafter designated as $\mathrm{C}$ ) began training. In order to control for time of testing, in both the aversive and appetitive phases, the running order was counterbalanced across subgroups. A subgroup consisted of either four or five animals randomly selected from within each group of nine subjects. The sound stimulus was presented simultaneously with the opening of the startbox door and terminated when the subject entered the goalbox. Reinforcement consisted of a $30-\mathrm{sec}$ retention in the goalbox with a tray of Purina Lab Chow.

\section{RESULTS}

Analyses of the last 7 days of appetitive training revealed that the control animals started and ran faster in the latter part of the appetitive phase than groups transferred from prior aversive training; the transferred groups did not differ significantly in the degree of suppression of start or run speeds.

Starting and running times were transformed into speed measures by taking the reciprocal of the median
Table 1

Means of Start and Run Speeds on Appetitive Days 7-13

\begin{tabular}{ccc}
\hline Group & Run Speed & Start Speed \\
\hline C & 77.16 & 265.64 \\
E-45 & 56.89 & 215.49 \\
A-15 & 53.44 & 204.82 \\
A-45 & 51.43 & 166.48 \\
E-15 & 41.32 & 225.26 \\
\hline
\end{tabular}

latency (in seconds) of each successive five trials for each subject and multiplying by 100 . Separate analyses of variance and individual comparisons for a 2 by 2 factorial design (aversive condition by number of aversive trials) with a single control group (Winer, 1962, pp. 263-267) were performed on start and run speeds on Appetitive Days 7-13. As in all previous research using this procedure, response suppression appeared only in the latter part of the appetitive phase.

The overall $\mathrm{F}$ for the control vs. all other groups on Days $7-13$ was significant for start speeds $(F=6.24$, $\mathrm{df}=1 / 40, \mathrm{p}<.05)$ and for run speeds $(\mathrm{F}=19.23$, $\mathrm{df}=1 / 40, \mathrm{p}<.001)$. See Table 1 for the mean start and run speeds for each group. As shown in Figure 1, the control animals steadily improved their running speeds over appetitive training, eventually surpassing the speed of each experimental group. Individual comparisons indicated that Group $C$ ran significantly faster than $E-15(t=4.73, d f=40, p<.01), E-45$ $(\mathrm{t}=2.68, \quad \mathrm{df}=40, \quad \mathrm{p}<.05), \quad \mathrm{A}-15 \quad(\mathrm{t}=3.13$, $\mathrm{df}=40, \mathrm{p}<.05)$, and $\mathrm{A}-45(\mathrm{t}=3.40$, $\mathrm{df}=40$, $p<.01)$, and started faster than $A-45(t=3.15$, $\mathrm{df}=40, \mathrm{p}<.05)$. No other source of variation (aversive condition, trials, or Aversive Condition by Trials interaction) was significant.

The five groups did not differ in their ad-lib body weights the day prior to beginning the appetitive phase. The largest difference in mean weight between
Figure 1. Running speed as a function of trials in the appetitive phase for subjects with prior aversive training (E-45, A-15, $A-45, E-15)$ and for subjects beginning training in the appetitive phase (control).

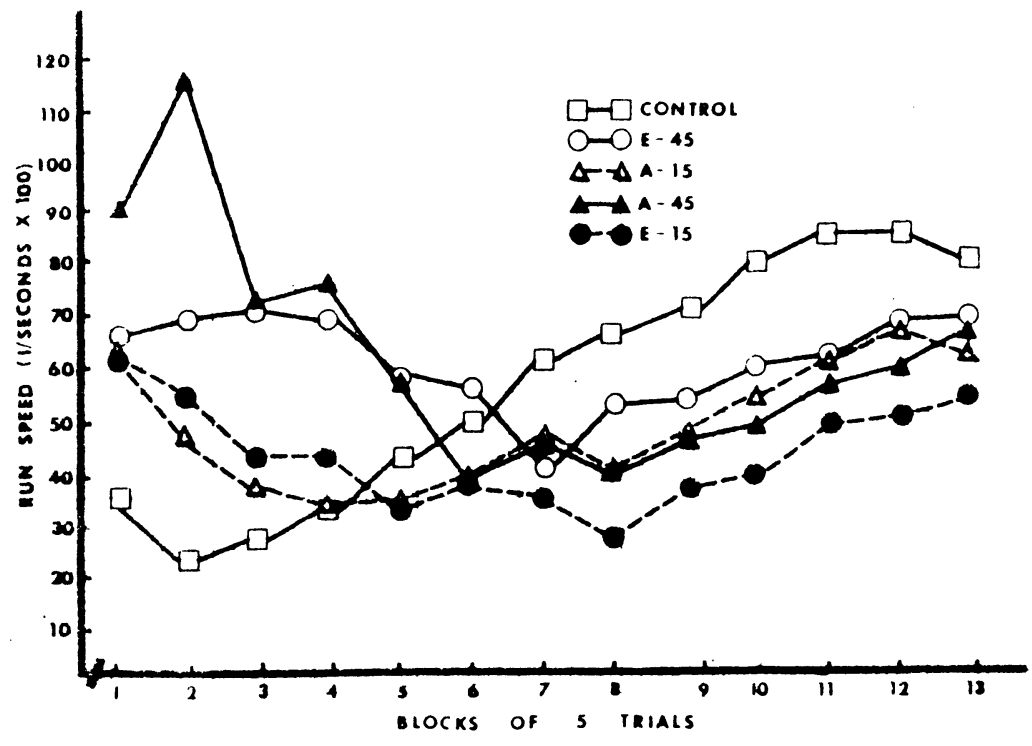


any two groups was only $8 \mathrm{~g} \quad(\mathrm{E}-15=388.33$, $\mathrm{A}-15=380 ; \mathrm{t}=.56, \mathrm{df}=16, \mathrm{p}>.05)$. Similarly, the largest difference in mean weight loss across appetitive training was only $10 \mathrm{~g}(\mathrm{E}-45=59.5$, $\mathrm{E}-15=49.33, \mathrm{t}=1.97, \mathrm{df}=16, \mathrm{p}>.05)$.

Factorial analyses of variances of speeds during the aversive phase followed the methods in Winer (1962, pp. 228-239). The tests were performed using all 15 trials for E-15 and A-15, but only the last 15 trials for E-45 and A-45. These trials were chosen because the comparison of E-15 and A-15 with the speeds of E-45 and A-45 on the final 15 trials should reflect any effect from extended training. Main effects were shown with start speeds for the aversive condition factor $(F=11.16, \mathrm{df}=1 / 32, \mathrm{p}<.01)$ in favor of the escape groups and for the trials factor $(F=27.94$, $\mathrm{df}=1 / 32, \mathrm{p}<.01)$ in favor of the groups receiving 45 trials. For run speeds, a main effect was shown for the aversive condition factor $(F=4.78, \mathrm{df} \doteq 1 / 32$, $\mathrm{p}<.05)$ with $\mathrm{E}-15$ faster than A-15 $(\mathrm{F}=5.67$, df $=1 / 32, p<.05)$. No interaction effects occurred. An inspection of combined starting and running times indicated that on each of the last 2 days of avoidance training. each of the 18 subjects in the two avoidance groups was avoiding on at least $80 \%$ of the trials. Thus, the avoidance subjects were in fact avoiding shock.

\section{DISCUSSION}

The present study replicates the basic suppression effect found by Babb and his associates in transferring rats from shock escape to appetitively motivated training. It also demonstrates that such suppression is not limited to procedures using escape trials in the aversively motivated phase. In addition, the effect survives both extended escape and extended avoidance trials in the aversive phase. These results do not conform to earlier theoretical predictions regarding the behavioral effects of combined drives (Hull. 1943).

Prior research has systematically eliminated alternative interpretations of suppression attributed to stimulus change due to new drive-reinforcement conditions (Babb \& Leask, 1969; Babb et al.. 1999; Bulgatz. 1968), and possible reductions in the readiness of previously shocked animals to consume food or water in the appetitive phase (Babb, 1963b: Babb \& Leask, 1969; Bulgatz. 1969; Although no explicit measures of food consumption were taken in the present study, there were no apparent differences between groups on this variable.)

Differential susceptibility to food deprivation during the appetitive phase may be ruled out as a possible explanation of suppression in the present study because: (a) the body weights of the previously shocked groups were quite similar to the control subjects at the beginning of food-training, and (b) there was no differential weight loss among groups during deprivation in the appetitive phase. Secondly, differential response speeds acquired under aversive motivation do not appear to alter the degree of suppression during hunger motivation. Significant main effects found for both starting and running speeds in the aversive phase were not noted in the appetitive phase.

Along with a previous finding that appetitive training suppresses runway performance on early trials during the extinction of an escape response (Babb \& Leask, 1969), the finding that suppression in appetitive training occurs in transfer from avoidance responding as well as from escape responding can be interpreted by assuming some kind of conflict between aversive and appetitive motivational conditions. Within the context of a theory of punishment, Estes (1969) has proposed a basic incompatibility between "amplifiers" originating from appetitive and aversive drive states. A related hypothesis suggests the existence of conflict between aversively trained and appetitively trained fractional anticipatory responses (Babb et al., 1969; Babb \& Leask, 1969). Although both points of view can handle the suppression findings, neither of them predicts a constant, or a diminished, amount of suppression of appetitive responding with increases in the number of prior aversive training trials. The present results did not provide any evidence that increasing numbers of aversive trials would produce increases in the amount of suppression occurring during later appetitive training. In fact, the trend on later trials was in the opposite direction. If we assume the amount of suppression of appetitive responding somehow reflects the degree of aversiveness generated by the shock trials, we would have to conclude that maximum aversiveness was achieved in a small number of trials. With a still larger number of shock trials than those given here, suppression might eventually have decreased. If that had happened, one would not have to hypothesize that the aversiveness of CS conditions diminished with extended numbers of shock trials. Rather, fear might have generalized to the goalbox more readily on earlier trials than on later ones. If the goalbox became less aversive with larger numbers of shock trials, then appetitive responding might have been suppressed to a smaller degree with the larger number of such trials.

Despite present and previous findings of suppression in transfer from aversive to appetitive training, some inconsistent findings have been reported. In one study (Babb, 1963a), after transfer from 60 shock-escape trials, subjects ran faster than controls for the first five trials of $47 \mathrm{~h}$ thirst-motivated training, although differences disappeared immediately and trials to extinction did not provide any significant differences between groups. This finding might be attributed to stimulus change effects adding to fear produced by the aversive training, particularly since experimental animals evidenced agitated behavior in the goalbox on the initial transfer trials. In addition, outside the context of attempting to transfer the same instrumental response between appetitive and aversive conditions, the CER procedure (Kamin, Brimer, \& Black, 1963) generally produces suppression. However, certain other procedures have reported an absence of suppression or the presence of additivity. Babb, Fitterman, and Paulson (1958), in several attempts, failed to obtain any effect of the application of conditioned appetitive stimuli on the extinction of discrete trial shuttlebox avoidance when the conditioned appetitive stimuli were manufactured "off the baseline" (Rescorla \& Solomon, 1967) both within the shuttlebox and in an outside "booth." Finally, although Bull (1970) reported findings suggestive of conflict between appetitive and aversive motivational states. Overmier and Bull (1970) and Overmier and Schwarzkopf (1974) report a summation of responding which they presume to have occurred as a function of the particular procedures they employed. They do not report their results as constituting an argument against the occurrence of conflict between appetitive and aversive motivational states, but suggest that "response cuing" may have produced their findings in spite of the possible presence of motivational conflicts (Overmier \& Bull, 1960; Overmier \& Schwarzkopf, 1974).

\section{REFERENCES}

BABB. H. Reinforcement and punishment of an escape response. Psychological Reports, 1963, 13. 542. (a)

BABB. H. Transfer between habits based on shock and thirst. Journal of Comparative and Physiological Psychology, 1963. 56. 318-313. (b)

Babb, H.. Bulgatz. M. G.. \& Matthews, L. J. Transfer from shock-escape to thirst or hunger-motivated responding. Journal of Comparative and Physiological Psychology. 1969. 67. 129-133.

Babb. H.. Fitterman, C. A..\& Paulson, J. H. Three attempts to determine the effects of an appetitive secondary reinforcer 
on the extinction of an avoidance response. Proceedings of the low a Academy of Science, 1958, 65, 385-392.

BABB. H.. \& LEASK, K. Response suppression after transfer from shock-escape to thirst-motivated training. Psychonomic Science. 1969. 14. 23-24.

Bulgatz. M. G. Variables affecting the suppression effect in transferring from aversive to appetitive motivation in the runway situation (Doctoral dissertation, University of Montana, 1968). Dissertation Abstracts, 1969, 29, 4862-B. (University Microfilms No. 69-9316)

Bull. J. A. An interaction between appetitive Pavlovian CSs and instrumental avoidance responding. Learning and Motivation. 1970. 1. 18-26.

Estes. W. K. Outline of a theory of punishment. In B. A. Campbell \& R. M. Church (Eds.), Punishment and Aversive Beharior. New York: Appleton-Century-Crofts, 1969.

Hull. C. L. Principles of behavior. New York: AppletonCentury-Croft. 1943.
Kamin. L. J., Brimer, C. J., \& Black, A. H. Conditioned suppression as a monitor of fear of the $C S$ in the course of avoidance training. Journal of Comparative and Physiological Psychology, 1963, 56, 497-501.

OVERMIER, J. B.. \& BUll. J. A.. IIIInfluences of appetitive Pavlovian conditioning upon avoidance behavior. In J. $\mathrm{H}$. Reynierse (Ed.), Current issues in animal learning: $A$ colloquim. Lincoln: University of Nebraska Press. 1970.

Overmier, J. B., \& Schwarzkopf, Karl H. Summation of food and shock based responding. Learning and Motivation. 1974. 5. 42-52.

Rescorla, R. A., \& Solomon, R. L. Two-process learning theory: Relationships between Pavlovian conditioning and instrumental learning. Psychological Review, 1967. 74. 151-182.

WINER. B. J. Statistical principles in experimental design. New York: McGraw-Hill. 1962.

(Received for publication February 3, 1976.) 